\title{
Hemorrhagic PRES: an unusual neurologic manifestation in two COVID-19 patients
}

\author{
PRES hemorrágica: uma manifestação neurológica incomum em dois pacientes \\ com COVID-19
}

Daniel Aguiar DIAS', Lara Albuquerque DE BRITO², Luciana de Oliveira NEVES², Roberto Guido Santos PAIVA², Octávio Alencar BARBOSA JÚNIOR², José Wagner Leonel TAVARES-JÚNIOR

Two patients with confirmed COVID-19 infection both manifesting with typical computerized tomography (CT) lung findings (less than $50 \%$ of lung parenchyma affected by ground-glass opacities) presented sudden altered mental status. By the time of neurologic deterioration, despite

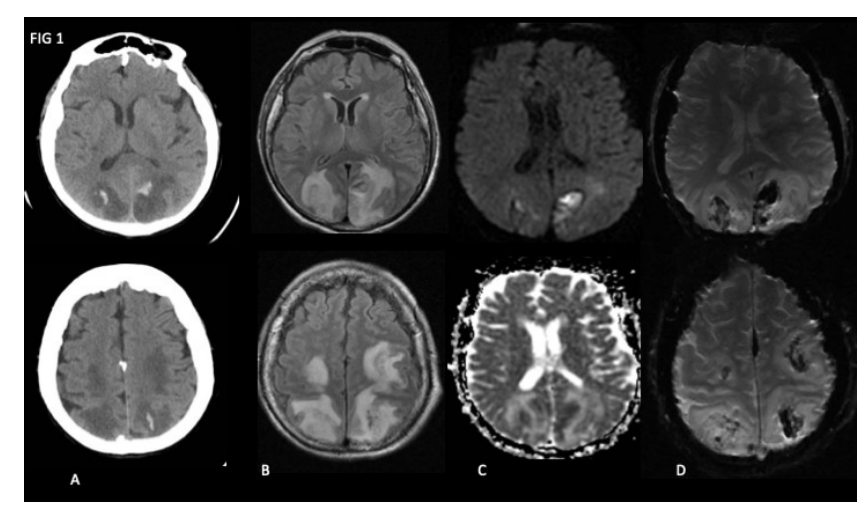

Figure 1. Patient 1: A - Non-contrast head computerized tomography revealing bilateral parieto-occipital subcortical hypodensities suggestive of vasogenic edema associated with bilateral hemorrhages in the same regions, findings compatible with hemorrhagic posterior reversible encephalopathy syndrome. B - Axial fluid-attenuated inversion recovery magnetic resonance imaging showing extensive bilateral parieto-occipital vasogenic edema; C - Diffusion weighted imaging and apparent diffusion coefficient map demonstrating restriction in some areas, probably due to the presence of blood products; D - Susceptibility weighted imaging showing areas of intense low signal, consistent with blood products. Magnetic resonance angiography (not shown) was normal. improved respiratory parameters, they were still in an intensive care unit under mechanical ventilation. Both patients had parieto-occipital cortico-subcortical hypodensities with associated acute hemorrhage foci on brain CT (Figures 1 and 2). Brain magnetic resonance imaging (MRI) was additionally obtained in one of those subjects, confirming areas of vasogenic edema and hemorrhage (Figure 1). Such findings are compatible with atypical posterior reversible encephalopathy syndrome (PRES), complicated by hemorrhage. Angiographic studies (magnetic resonance angiography MRA - for one patient and CT angiography - CTA - for the other) excluded venous thrombosis.

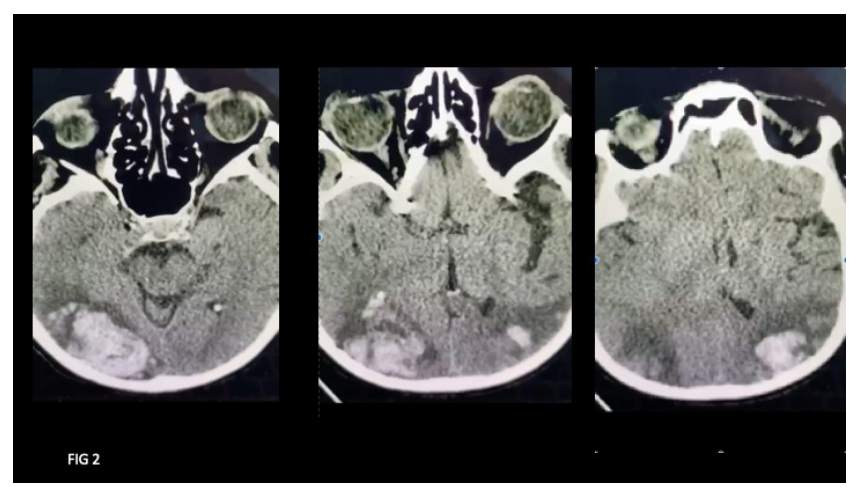

Figure 2. Patient 2: Non-contrast head computerized tomography showing bilateral massive subcortical intra-parenchymal acute hematomas surrounded by edema. Computerized tomography angiography (not shown) was normal.

\footnotetext{
UUniversidade Federal do Ceará, Hospital Universitário Walter Cantídio, Setor de Radiologia, Fortaleza CE, Brazil.

${ }^{2}$ Hospital São Carlos, Fortaleza CE, Brazil.

${ }^{3}$ Universidade Federal do Ceará, Hospital Universitário Walter Cantídio, Fortaleza CE, Brazil.

Daniel Aguiar DIAS (DD https://orcid.org/0000-0002-9122-2770; Lara Albuquerque DE BRITO (D) https://orcid.org/0000-0002-6070-1808;

Luciana de Oliveira NEVES (D) https://orcid.org/0000-0002-8524-4308; Roberto Guido Santos PAIVA (ID https://orcid.org/0000-0002-6647-7982;

Octávio Alencar BARBOSA JÚNIOR (D) https://orcid.org/0000-0002-7028-6556; José Wagner Leonel TAVARES-JÚNIOR (D) https://orcid.org/0000-0002-7405-4998

Correspondence: Daniel Aguiar Dias; E-mail: daniel_aguiar@hotmail.com

Conflict of interest: There is no conflict of interest to declare.

Authors' contributions: DAD: equal contributions to the design or development of the study; to the collection, analysis and interpretation of data; to the writing of the article and its critical revision; to the approval of the final version. LAB: design or development of the study. LON: approval of the final version. RGSP: writing of the article. OABJ: data collection, analysis and interpretation of data. JWLTJ: equal contributions to the design or development of the study; the collection, analysis and interpretation of data; the writing of the article and its critical revision; and the approval of the final version.

Received on August 12, 2020; Received in its final form on September 14, 2020; Accepted on September 17, 2020.
} 
Critically-ill patients with COVID-19 have an extreme inflammatory reaction, causing a cytokine storm syndrome that may damage the blood-brain barrier and complicate with PRES ${ }^{1}$. The associated hemorrhage seen in our patients may also be explained by coagulation impairment, another common complication reported in COVID-19 patients².

\section{References}

1. Mehta P, McAuley DF, Brown M, Sanchez E, Tattersall RS, Manson

JJ; HLH Across Specialty Collaboration, UK. COVID-19: consider cytokine storm syndromes and immunosuppression. Lancet. 2020

Mar;395(10229):1033-4. https://doi.org/10.1016/S0140-6736(20)30628-0
2. Franceschi AM, Ahmed O, Giliberto L, Castillo M. Hemorrhagic Posterior Reversible encephalopathy syndrome as a manifestation of COVID-19 infection. AJNR Am J Neuroradiol. 2020 Jul;41 (7):1173-6. https://doi.org/10.3174/ajnr.A6595 